\title{
Ablasyo Plasenta Olgularının Retrospektif Olarak Değerlendirilmesi
}

THE RETROSPECTIVE ANALYSIS OF CASES WITH ABLATIO PLACENTA

\author{
Burcu ARTUNÇ ÜLKÜMEN, Halil Gürsoy PALA, Esat ÇALIK, Faik Mümtaz KOYUNCU \\ Celal Bayar Üniversitesi Tıp Fakültesi Kadın Hastalıkları Ve Doğum Anabilim Dalı
}

\begin{abstract}
ÖZET
Amaç: Kliniğimizde ablasyo plasenta tanısı almış hastaların maternal özellikleri, risk faktörleri ve fetal sonuçlarının değerlendirilmesi amaçlandı.

Yöntem: Ocak 2012-Mart 2014 zaman aralığ 1 içerisinde takip edilen 30 ablasyo plasenta olgusu retrospektif olarak analiz edildi. Aynı zaman aralığında kliniğimizde takip edilmiş olan gebelikler arasından 30 sağlıklı tekil gebelik gestasyonel hafta ile eşleştirilerek kontrol grubu olarak seçildi. Anne yaşı, gravida, parite, ortalama gebelik haftası, maternal risk faktörleri, kan transfüzyon gerekliliği, ultrasonografik olarak ablasyo bulgusu izlenip izlenmediği ve doğum şekli ile ilgili veriler değerlendirildi.

Bulgular: Kliniğimizde ablasyo plasenta insidansı \%0,99 olarak tespit edildi. Bu oran literatür verileri ile uyumlu bulundu. Dekolman olgularının yaş ortalaması $29,59 \pm 5,68$ (aralık: 18-39), gravida ortalaması 1,76 $\pm 1,06$ (aralık: 1-6), parite ortalaması 0,55 $\pm 0,83$ (aralık:0-3) olarak tespit edildi. Ortalama gebelik haftası 32,16 $\pm 3,54$ (aralık: 25-38) olarak bulundu. Olgularin 11'inde (\%36,7) ultrasonografik olarak dekolman bulgusu saptand1. 22 olguda $(\% 73,3)$ eksternal kanama mevcut iken, 8 olguda $(\% 26,7)$ eksternal kanama saptanmadi. 16 olguda $(\% 53,3)$ hipertansiyon mevcuttu ve kontrol grubu ile karşılaştırıldığında anlamlı fark saptandı $(p=0,001)$. Olguların hepsi sezaryen ile doğurtuldu. 7 olguda $(\% 23,3)$ sigara kullanım öyküsü mevcuttu ve kontrol grubu ile anlamlı fark izlendi $(p=0,046)$. Sigara kullanımı ve hipertansiyon varlığı tek başına dekolman plasenta açısından bağımsız birer risk faktörü olarak bulundu (sırası ile OR: 6.38 ve 21.32 ).

Sonuç: Ablasyo plasenta günümüzde halen maternal ve perinatal morbidite ve mortalitenin sı nedenlerinden birisidir. Özellikle sigara içen ve hipertansif gebeler ablasyo plasenta açısından artmış risk altındadır. Tanıda hastanın kliniği önemlidir. Ultrasonografi olguların ancak \%40-50 kadarında yardımcı olabilir. Sonografik muayenenin asıl amacı plasenta previa durumunu ekarte etmektir.

Anahtar sözcükler: Ablasyo plasenta, ultrasonografi, maternal risk faktörleri

SUMMARY

Objective: It is aimed to evaluate the maternal characteristics, risk factors and fetal outcomes in patients diagnosed as ablatio placenta in our clinic.

Material and method: 30 pregnancies diagnosed as ablatio placenta between January 2012 - March 2014 were analysed retrospectively. 30 healthy singleton pregnancies during same period was selected as control group, matched fort he gestational age. Maternal age, gravida, parity, mean gestational week, maternal risk factors, need for
\end{abstract}

Burcu ARTUNÇ ÜLKÜMEN

Celal Bayar Üniversitesi

Tıp Fakültesi

Kadın Hastalıkları Ve Doğum AD

MANISA 
transfusion, ultrasonographic findings and mode of delivery were evaluated.

Results: The incidence of ablatio placenta was $0.99 \%$ in our clinic and was compatible with literature. The mean maternal age was $29.59 \pm 5.68$ (range: 18-39), mean gravida was $1.76 \pm 1.06$ (range:1-6), and mean parity was $0.55 \pm 0.83$ (range: 0-3). Mean gestational week was $32.16 \pm 3.54$ (range: $25-38$ ). Ultrasonograhic findings confirmed ablatio placenta in 11 cases (36.7\%). External bleeding was in 22 cases $(73.3 \%)$; bleeding was not evident for 8 cases $(26.7 \%) .16$ cases $(53.3 \%)$ had hypertension. Hypertension was signficantly more common in pregnancies complicated with ablatio placenta $(p<0.001)$. All ablatio cases were delivered with cesarean. 7 cases $(23.3 \%)$ were smokers and this was significantly higher compared with the control group $(p=0.046)$. Smoking and hypertension were independent risk factors for ablatio placenta (OR: 6.38 and 21.32 , respectively).

Conclusion: Ablatio placenta is still a common cause of maternal and perinatal morbidity and mortality. Especially smokers and hypertensive pregnancies have increased risk. The diagnosis depends on the clinical features of the patient. Ultrasonography may be helpful only up to $40-50 \%$ of patients. The main aim for ultrasonographic evaluation is to rule out placenta previa.

Key words: Ablatio placenta, ultrasonography, maternal risk factors

Tüm gebeliklerin yaklaşık olarak \%4’ü 28. gebelik haftasından sonra vajinal kanama ile komplike olmaktadır (1). Bu kanamaların \%80'i ablasyo plasenta nedeni ile oluşmaktadır (2). Ablasyo plasenta; plasentanın uterusa implante olduğu alandan, desidua basalis içine olan kanama sonucunda fetusun doğumu henüz gerçekleşmeden tam yada kısmi olarak ayrılmasıdır (3). Ablasyonun derecesi geniş bir klinik yelpazede izlenebilir: Maternal ve yenidoğan sonuçlarını hafif etkileyebilen yada hiç etkilemeyen çok küçük plasental ayrılmalarından, fetal ölüm ve ağır maternal morbidite yaratabilecek ciddi plasental ayrılmaya kadar bir spektrum içerisinde olabilir $(4,5)$.

Ablasyo plasenta, gebeliklerin yaklaşık olarak \%0,5 1,8 oranında izlenmektedir $(6,7)$. Maternal kronik hipertansiyon, preeklampsi, maternal sigara kullanımı, ileri maternal yaş, grandmultiparite, çoğul gebelik, maternal trombofili, polihidramnios bilinen risk faktörleridir (8). Ablasyo plasenta; artmış maternal ve perinatal morbidite ve mortalite için risk taşımaktadır. Bu nedenle erken dönemde tanısı önemlidir (1). Massif kan transfüzyonu gerekliliği, hemorajik şok, akut böbrek yetmezliği ve Dissemine Intravasküler Koagülasyon (DİK) dekolman plasentanın en sık karşılaşılan maternal komplikasyonlarıdır. Prematürüte ve prematüriteye bağlı sorunlar, fetal hipoksi ve fetal ölüm ise en sık karşılaşılan perinatal komplikasyonlardır (9).

Bu çalışmada, kliniğimizde ablasyo plasenta tanısı almış hastaların maternal özellikleri, risk faktörleri ve fetal sonuçlarının değerlendirilmesi amaçlandı.

\section{GEREÇ VE YÖNTEM}

Ocak 2013 - Mart 2014 zaman aralığı içerisinde takip edilen 30 ablasyo plasenta olgusu retrospektif olarak analiz edildi. Aynı zaman aralığında kliniğimizde takip edilmiş olan 30 sağlıklı tekil gebelikler gestasyonel hafta ile eşleştirilerek kontrol grubu olarak seçildi. Tüm veriler dosya kayıtlarının incelenmesi ile elde edildi. Anne yaşı, gravida, parite, doğumda ortalama gebelik haftası, maternal risk faktörleri, kan transfüzyon gerekliliği, ultrasonografik olarak ablasyo bulgusu izlenip izlenmediği ve doğum şekli ile ilgili veriler değerlendirildi. Yenidoğanlar ise, doğum haftası ve apgar skorları açısından değerlendirildi. Dekolman tanısı, doğum sonrasında makroskopik değerlendirmede dekolman alanın görülmesi ile kesinleştirildi. Elde edilen veriler bilgisayarda SSPS v20 programı kullanılarak analiz edildi. Gruplar arası fark, ki-kare ve t-test kullanılarak değerlendirildi. Regresyon analizi ile bağımsız risk faktörleri ve olasılık oranları hesaplandı. $p<0,05$ değeri istatistiksel anlamlı olarak değerlendirildi.

\section{BULGULAR}

Kliniğimizde ablasyo plasenta insidansı \%0,99 olarak tespit edildi. $\mathrm{Bu}$ oran literatür verileri ile uyumlu bulundu. Dekolman olgularının yaş ortalaması 29,59 $\pm 5,68$ (aralık: 18-39), gravida ortalaması 1,76 $\pm 1,06$ (aralık: 1-6), parite ortalaması $0,55 \pm 0,83$ (aralık: $0-3$ ) olarak tespit 
edildi. Ortalama gebelik haftası 32,16 \pm 3,54 (aralık: 25-38) olarak bulundu (Tablo I). Olgulara ait laboratuvar bulguları Tablo II'de izlenmektedir. Olguların 11'inde (\%36,7) ultrasonografik olarak dekolman bulgusu saptandi. 22 olguda $(\% 73,3)$ eksternal kanama mevcut iken, 8 olguda $(\% 26,7)$ eksternal kanama saptanmadi. 16 olguda $(\% 53,3)$ hipertansiyon mevcuttu ve kontrol grubu ile karşılaştırıldığında anlamlı fark saptandı $(p=0,001)$. Olguların hepsi sezaryen ile doğurtuldu. 13 olguda $(\% 43,3)$ kan transfüzyonu gerekliliği oldu. 7 olguda $(\% 23,3)$ sigara kullanım öyküsü mevcuttu ve kontrol grubu ile anlamlı fark izlendi $(p=0,046)$. Sigara kullanımı ve hipertansiyon varlığı tek başına dekolman plasenta açısından bağımsız birer risk faktörü olarak bulundu (sırası ile OR: 6.38 ve 21.32).

\section{TARTIŞMA}

Dekolman plasenta sıklığ1 yaklaşık olarak \%0,5-1,8 arasındadır (7). Kliniğimizde de literatür ile uyumlu olarak ablasyo plasenta insidans $\% 0,99$ olarak tespit edildi. Dekol- man plasentanın etiyolojisi kesin olarak aydınlatılamamış olmakla birlikte tanımlanmış başlıca risk faktörleri grandmultiparite, ileri anne yaşı, preeklampsi, hipertansiyon, trombofili ve polihidramnios durumlarıdır (8). Yap1lan çalışmalarda maternal yaş ve parite arttıkça dekolman riskinin arttığını göstermiştir $(2,10)$. Bizim olgularımızda yaş ortalaması 29,59 $\pm 5,68$ (aralık: 18-39) olarak bulundu ve control grubundan anlamlı olarak yüksekti $(p=0,011)$. Ülkemizde yapılan dekolman plasenta olgularının değerlendirildiği diğer çalışmalarda ortalama maternal yaş ise; Adalı ve ark tarafından $30,18 \pm 6,60$, Yılmaz ve ark tarafindan ise $32,4 \pm 8,9$ olarak bulunmuştur $(7,9)$. Olgularımızın gravida ortalaması 1,76 $\pm 1,06$ (aralık: 1-6), parite ortalaması 0,55 $\pm 0,83$ (aralık:0-3) olarak bulundu. Adalı ve ark tarafından ortalama gravida $5,83 \pm 3,41$ ve Yılmaz ve ark tarafından 4,26 $\pm 2,45$ olarak tespit edildi $(7,9)$. Bizim çalışmamızda maternal yaş ve ortalama gravida-parite değerleri daha düşük olarak tespit edildi.

Tablo I. Dekolman plasenta olgularının demografik özellikleri

\begin{tabular}{lccc}
\hline & $\begin{array}{c}\text { Dekolman plasenta grubu } \\
\mathbf{n = 3 0} \text { (ort } \pm \text { S) }\end{array}$ & $\begin{array}{c}\text { Kontrol grup } \\
\mathbf{n = 3 0} \text { (ort } \pm \text { S) }\end{array}$ & $p$ \\
\hline Maternal yaş & $29,59 \pm 5,68$ & $25,82 \pm 5,16$ & $0,011^{*}$ \\
Gravida & $1,76 \pm 1,06$ & $2,04 \pm 1,23$ & 0,366 \\
Parite & $0,55 \pm 0,83$ & $0,75 \pm 0,89$ & 0,386 \\
Abortus & $0,21 \pm 0,62$ & $0,38 \pm 0,58$ & 0,345 \\
Gebelik haftas1 & $32,16 \pm 3,54$ & $33,42 \pm 4,23$ & 0,324 \\
Apgar 1.dk & $5,58 \pm 1,66$ & $8,22 \pm 0,74$ & $0,010^{*}$ \\
Apgar 5.dk & $8,12 \pm 1,36$ & $9,65 \pm 0,46$ & $0,042^{*}$ \\
\hline
\end{tabular}

*Istatistiksel olarak anlaml

Tablo II. Dekolman plasenta olgularının laboratuvar özellikleri

\begin{tabular}{|c|c|c|c|}
\hline & $\begin{array}{c}\text { Dekolman plasenta grubu } \\
n=30(\text { ort } \pm S)\end{array}$ & $\begin{array}{l}\text { Kontrol grup } \\
n=30(\text { ort } \pm S)\end{array}$ & $p$ \\
\hline $\mathrm{Hb}(\mathrm{g} / \mathrm{dl})$ & $8,90 \pm 3,23$ & $9,20 \pm 2,60$ & $0,050^{*}$ \\
\hline AST (U/1) & $45,12 \pm 13,16$ & $18,14 \pm 5,28$ & $0,002 *$ \\
\hline ALT (U/1) & $26,56 \pm 4,74$ & $21,89 \pm 6,70$ & 0,560 \\
\hline
\end{tabular}

*Istatistiksel olarak anlaml 
Bunun nedeninin, refere bir merkez olmamız nedeni ile çevre il ve ilçelerden sevk edilen primigravid genç preeklamptik gebelerin yoğunluğuna bağlı olabileceğini düşünüyoruz. Çünkü bizim serimizde hipertansiyon oranı daha önceki çalışmalarda tanımlanan oran ve dekolman için risk oranından çok daha yüksek olarak tespit edildi. Adalı ve ark hipertansiyon oranını \%30 olarak belirtmişlerdir (7). Ancak bizim olgularımızda hipertansiyon ve preeklampsi yaklaşık olarak \%53,3 hastada izlendi ve ayrıca preeklampsi varlığı dekolman plasenta açısından bağımsız bir risk faktörü olarak değerlendirildi (LR 21.32). Ananth ve ark tarafından yapılan bir çalışmada, dekolman riskinin preeklampsi ve kronik hipertansiyona eklenen preeklampsi varlığında arttığını; sadece kronik hipertansiyon varlığında riskin artmadı̆̆ını ileri sürmüşlerdir. Kronik hipertansiyon zemininde riskin daha çok pariteye bağımlı olduğunu bildirmişlerdir (11).

Dekolman plasenta açısından önemli ve önlenebilir bir risk faktörü sigara içimidir. Çalışmamızda dekolman grubunda sigara içen sayısında anlamlı fark olduğu ve ayrıca dekolman gelişimi açısından sigaranın bağımsız bir risk faktörü olduğunu saptadık. Sigara kullanımı genel olarak içmeyenlere göre dekolman riskini 2.5 kat arttırmaktadır (12). İçilen sigara miktarı ile dekolman plasenta arasında doz bağımlı ilişki saptanmıştır $(13,14)$. Ayrıca gebelik öncesinde sigarayı bırakan kişilerde bile artmış risk devam etmektedir (15).

Geç gebelik kanamalarında ultrasonografi tanısal yaklaşımın bir parçası olmakla birlikte, dekolman plasenta olgularında esas kullanım amacı plasenta previa durumunu ekarte etmek içindir. Dekolman plasenta olgularının en az \%50'sinde ultrasonografik bulgu saptanmaz (16). Ultrasonografik olarak tespit edilecek görünüm dekole alanine yerleşimine ve kanama miktarına ve süresine gore değişebilir. Akut kanamanın erken döneminde, uterus içerisinde kan ve pıhtı birikimi, plasenta ekojenitesi ile karşılaştırıldığında hiperekoik yada izoekoik görünümde izlenirler. Kronik ablasyo olgularında ise, oluşan hematom haftalar içerisinde çözülür ve yaklaşık 2 hafta sonunda hipoekoik ve sonrasında da aşama aşama sonolusen görünüme kavuşur (17). Ancak özellikle akut kanamada, özellikle de vajinal kanamanın olduğu durumlarda, uterus içerisinde biriken kan ve pıhtı olma- yacağından spesifik bir ultrason bulgusu da çok beklenmemelidir. Sonuç olarak, ultrason bulgusunun olmaması kesinlikle dekolman olasılığını ekarte ettirmemektedir (18).

Özetle, ablasyo plasenta günümüzde halen maternal ve perinatal morbidite ve mortalitenin sık nedenlerinden birisidir. Özellikle önceki gebeliinde dekolman öyküsü olan, sigara içen ve hipertansif gebeler ablasyo plasenta açısından artmış risk altındadır. Tanı klinik bulgulara dayanır. Ultrasonografi olguların ancak \%40-50 kadarında yardımcı olabilir. Sonografik muayenenin asıl amacı plasenta previa durumunu ekarte etmektir.

\section{KAYNAKLAR}

1. Keskin N. Preterm Plasenta Previa ve Ablasyo Plasenta Vakalarında Sezaryen Endikasyonlarının Tartışılması. Düzce Tıp Fakültesi Dergisi 2009;11:54-58.

2. Ananth CV, Berkowitz GS, Savitz DA, Lapinski RH. Placental abruption and adverse perinatal outcome. JAMA 1999; 282:1646-51.

3. Spinillo A, Fazzi E, Stronati M, et al. Severity of abruptio placentae and neurodevelopmental outcome in low birth weight infants. Early Hum Dev 1993; 35:45-54.

4. Oyelese Y, Ananth CV. Placental abruption. Obstet Gynecol 2006; 108:1005-1016.

5. Ananth CV, Smulian JC, Srinivas N, et al. Risk of infant mortality among twins in relation to placental abruption: contributions of preterm birth and restricted fetal growth. Twin Res Hum Genet 2005; 8:524-531.

6. Cunningham FG, Leveno KJ, Bloom SL, Hauth JC, Rouse DJ, Spong CY. Obstetrical Hemorrhage. In: Williams obstetrics. 23nd ed. New York: Mc Graw-Hill 2010; 527-547.

7. Adalı E, Yıldızhan R, Kolusarı A, Kurdoglu M, Cim N, Ozgokce C. Dekolman plasenta olgularının retrospektif olarak değerlendirilmesi. Van Tıp Dergisi 2009; 16 :14-18.

8. Hladky K, Yankowitz J, Hansen WF. Placental abruption. Obstet Gynecol Surv 2002; 57:299-305.

9. Yılmaz M, Isaoglu U, Delibas IB ve ark. Dekolman Plasenta: Epidemiyoloji, Risk Faktörlerinin Analizi, Fetal ve Maternal Sonuçlar. Sakaryamj 2013;3:126-130.

10. Raymond EG, Mills JL. Placental abruption. Maternal risk factors and associated fetal conditions. Acta Obstet Gynecol Scand 1993;72:633-639. 
11. Ananth CV, Peltier MR, Kinzler WL, Smulian JC, Vintzileos AM. Chronic hypertension and risk of placental abruption: is the association modified by ischemic placental disease? Am J Obstet Gynecol 2007;197:273277.

12. Cnattingius S. Maternal age modifies the effect of maternal smoking on intrauterine growth retardation but not on late fetal death and placental abruption. Am J Epidemiol 1997; 145:319-323.

13. Raymond EG, Mills JL. Placental abruption: maternal risk factors and associated fetal conditions. Acta Obstet Gynecol Scand 1993; 72:633-639.

14. Kennare R, Heard A, Chan A. Substance use during pregnancy: risk factors and obstetric and perinatal out- comes in South Australia. Aust N Z J Obstet Gynaecol $2005 ; 45: 220-225$.

15. Castles A, Adams EK, Melvin CL, et al. Effects of smoking during pregnancy: five meta-analyses. Am J Prev Med 1999; 16:208-215.

16. Glantz C, Purnell L. Clinical utility of sonography in the diagnosis and treatment of placental abruption. $J$ Ultrasound Med 2002; 21:837-840.

17. Nyberg DA, Cyr DR, Mack LA, et al. Sonographic spectrum of placental abruption. AJR Am J Roentgenol 1987; 148:161-164.

18. Rasmussen S, Irgens LM, Dalaker K. Outcome of pregnancies subsequent to placental abruption: a risk assessment. Acta Obstet Gynecol Scand 2000; 79:496-501. 